\title{
Correction to: Effect of Mixed-Ligands Copper Complex on the Corrosion Inhibition of Carbon Steel in Sulfuric Acid Solution
}

\author{
R. N. El-Tabesh ${ }^{1}$ A. M. Abdel-Gaber ${ }^{1,2} \cdot$ H. H. Hammud ${ }^{3} \cdot$ R. Al-Oweini ${ }^{1,4}(\mathbb{C}$
}

Published online: 3 March 2020

○) Springer Nature Switzerland AG 2020

\section{Correction to: \\ Journal of Bio- and Tribo-Corrosion (2020) 6:29 \\ https://doi.org/10.1007/s40735-020-0323-8}

In the original article R. Al-Oweini's last name is incorrect. It is correct as reflected here.
R. Al-Oweini's ORCID ID is https://orcid. org/0000-0003-1891-3716.

Publisher's Note Springer Nature remains neutral with regard to jurisdictional claims in published maps and institutional affiliations.
The original article can be found online at https://doi.org/10.1007/ s40735-020-0323-8.

A. M. Abdel-Gaber

ashrafmoustafa@yahoo.com

1 Department of Chemistry, Faculty of Science, Beirut Arab University, Beirut, Lebanon

2 Department of Chemistry, Faculty of Science, Alexandria University, Ibrahimia, P.O. Box 426, Alexandria 21321, Egypt

3 Chemistry Department, Faculty of Science, King Faisal University, Al-Ahsa 31982, Saudi Arabia

4 Kamal A. Shair Central Research Science Laboratory,

Faculty of Arts and Sciences, American University of Beirut, Riad El-Solh 1107 2020, Beirut, Lebanon 